\title{
Near-field strain observations of the October 2013 Ruisui, Taiwan, earthquake: source parameters and limits of very short-term strain detection
}

\author{
Alexandre Canitano ${ }^{1 *}$, Ya-Ju Hsu ${ }^{1}$, Hsin-Ming Lee ${ }^{1}$, Alan T. Linde ${ }^{2}$ and Selwyn Sacks ${ }^{2}$
}

\begin{abstract}
Volumetric strain changes associated with the October $2013 M_{w} 6.2$ Ruisui earthquake were recorded by a network made up with four borehole Sacks-Evertson dilatometers in eastern Taiwan. These instruments are located within 25-30 km of the seismic source providing also high-resolution near-field observations. Co-seismic offsets larger than a few $10^{2} \mathrm{n} \epsilon$ were seen by most of the sensors. We relocated the $30 \mathrm{~km} \times 30 \mathrm{~km}$ fault plane through a grid-search approach. The inferred fault parameters $\left(217^{\circ}, 48^{\circ}, 49^{\circ}\right)$ are in reasonable agreement with those resulting from the inversions of long-period seismic waves $\left(209^{\circ}, 59^{\circ}, 50^{\circ}\right)$ as well as from GPS data inversion $\left(200^{\circ}, 45^{\circ}, 42^{\circ}\right)$. Moreover, analysis of the $100-\mathrm{Hz}$ sampling data $10 \mathrm{~s}$ before seismic radiations indicate no pre-seismic strain change emergent from the instrumental noise level (from $10^{-2}$ to $10^{-1} \mathrm{n} \epsilon$ ). Such an observation sets limits on any precursory change in a nucleation area, taken to have dimensions of about 250-300 m, seconds before the mainshock. Thus, the upper limit of any pre-seismic moment is about $10^{-5} \%$ of the total seismic moment of the Ruisui earthquake.
\end{abstract}

Keywords: Near-field strain record; Earthquake model; Limits of pre-seismic strain

\section{Introduction}

The Ruisui earthquake occured on 31 October 2013 on the Longitudinal Valley (LV) in eastern Taiwan, close to the town of Ruisui (Fig. 1, Rueisuei). The event was the third $M_{w} \geq 6$ event occurring in Taiwan, during 2013, following the 27 March and 2 June Nantou sequence (Chuang et al. 2013). The LV, which is considered as an active collision boundary between the Eurasian plate (EU) and the Philippine Sea plate (PSP) (Barrier and Angelier 1986; Chai 1972), is accounting for more than one third of the $80 \mathrm{~mm} \cdot \mathrm{y}^{-1}$ of oblique plate convergence (Yu et al. 1997, 1999) (see Fig. 1). The LVF is separating two different geological regions: the Coastal Range to the east and the Central Range to the west. The deformation along the LV is mostly accommodated by two large structures: the Longitudinal Valley fault (LVF) and the Central Range

\footnotetext{
*Correspondence: canitano@earth.sinica.edu.tw

${ }^{1}$ Institute of Earth Sciences, Academia Sinica, P.O. Box 1-55, Nankang, Taipei, Taiwan

Full list of author information is available at the end of the article
}

fault (CRF). The $60^{\circ}$ east-dipping LVF, which represents the main active structure of the $\mathrm{LV}$, is characterized by high rates of oblique slip on its southern segment and by primary left-lateral strike-slip on its northern segment (Shyu et al. 2005; Yu and Kuo 2001). The CRF, dipping $50^{\circ}-60^{\circ}$ westward underneath the eastern flank of the Central Range, is associated with the fast uplift of the Central Range (Shyu et al. 2006). The Ruisui earthquake is believed to rupture a $30-35-\mathrm{km}$-long segment of this northeast-southwest trending CRF with a primary thrust mechanism, in agreement with the tectonic stress regime in this region. However, the existence of the CRF has long been debated since its introduction (Biq 1965). The earthquake report of the Central Weather Bureau (CWB) of Taiwan indicated an epicenter located at a depth of about $15 \mathrm{~km}$ at the position $\left(121.348^{\circ} \mathrm{E}, 23.566^{\circ} \mathrm{N}\right)$. Source parameters inferred from GPS data inversion (see (see Fig. 2 and the 'Preliminary GPS model' section) for details) and seismic waveform inversion (Lee et al. 2014) were reported soon after its occurrence. Both indicate a thrust-fault mechanism with a strike, dip, and rake angles

\section{是 Springer}

(c) 2015 Canitano et al. Open Access This article is distributed under the terms of the Creative Commons Attribution 4.0 International License (http://creativecommons.org/licenses/by/4.0/), which permits unrestricted use, distribution, and reproduction in any medium, provided you give appropriate credit to the original author(s) and the source, provide a link to the Creative Commons license, and indicate if changes were made. The Creative Commons Public Domain Dedication waiver (http:// creativecommons.org/publicdomain/zero/1.0/) applies to the data made available in this article, unless otherwise stated. 


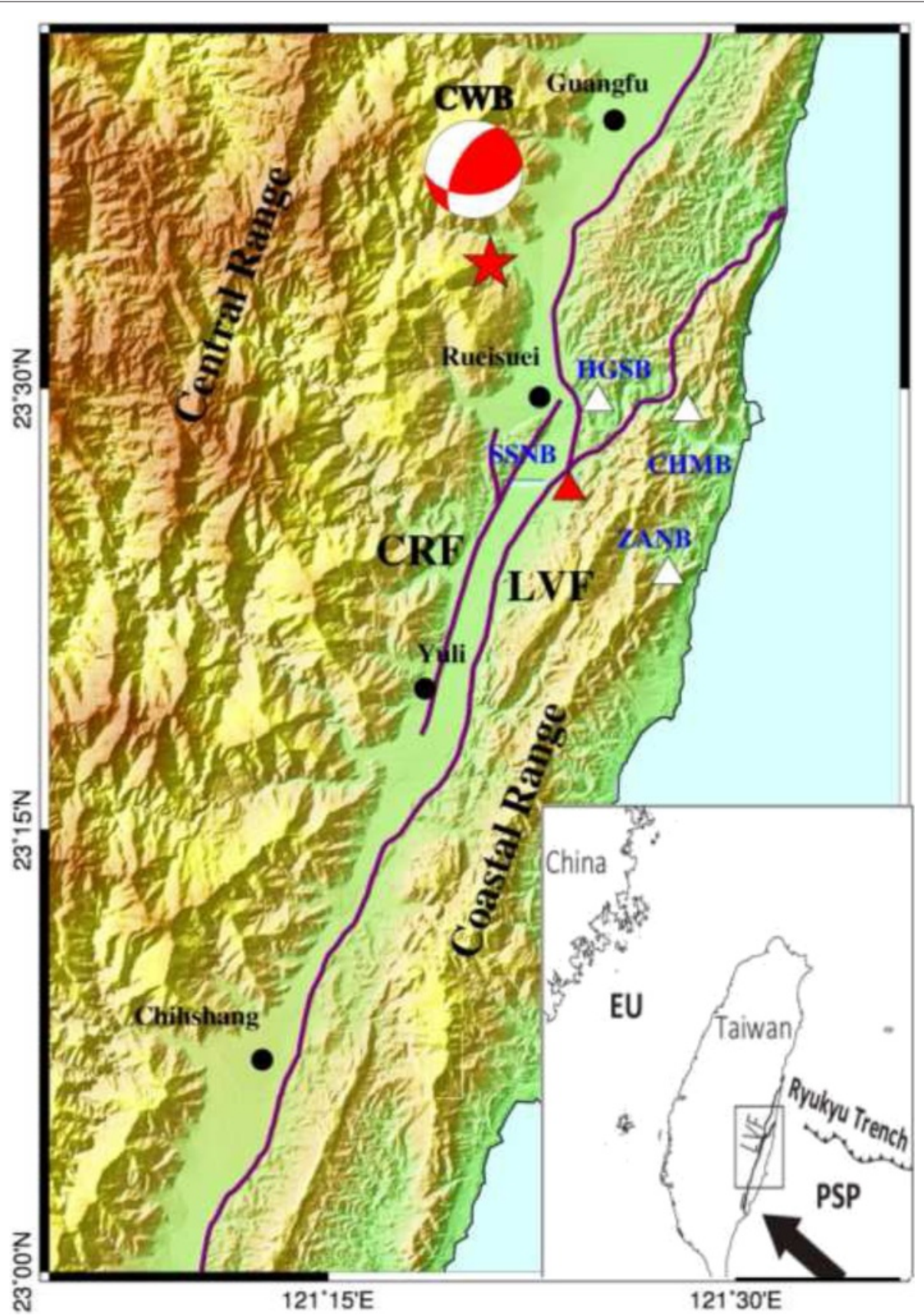

Fig. 1 Map of the major structures along the Longitudinal Valley. LVF east-dipping Longitudinal Valley fault, CRF west-dipping Central Range fault. The red and white triangles denote the three-component (SES-3) and the dilatometer (SES-1) sensors established on the central Ruisui-Chimei site, respectively. The red star denotes the epicenter location of the $M_{w} 6.2$ Ruisui earthquake from Central Weather Bureau (CWB) of Taiwan and its focal mechanism. Inset shows the regional tectonics with the bold arrow indicating the plate convergence between the Eurasian plate (EU) and the Philippine Sea plate (PSP) (Yu et al. 1997)

varying from about $200^{\circ}$ to $209^{\circ}, 45^{\circ}$ to $59^{\circ}$, and $42^{\circ}$ to $50^{\circ}$, respectively, and with a moment magnitude of about 6.2 .

Furthermore, this shock occurred near a network made up of four Sacks-Evertson borehole strainmeters three dilatometers SES-1, one three-component SES-3) (Sacks et al. 1971). Due to its proximity with the stations (varying from about 20 to $30 \mathrm{~km}$, see triangles on Fig. 1), this earthquake provides one of the best examples of nearfield strain data yet, both before or during a magnitude larger than 6.0 event. Indeed, a few analyses of nearfield strain records of moderate earthquakes have been reported so far; most have been conducted on borehole dilatometers in California during mainshocks along the San Andreas fault, as the 1990 Loma Prieta (Johnston et al. 

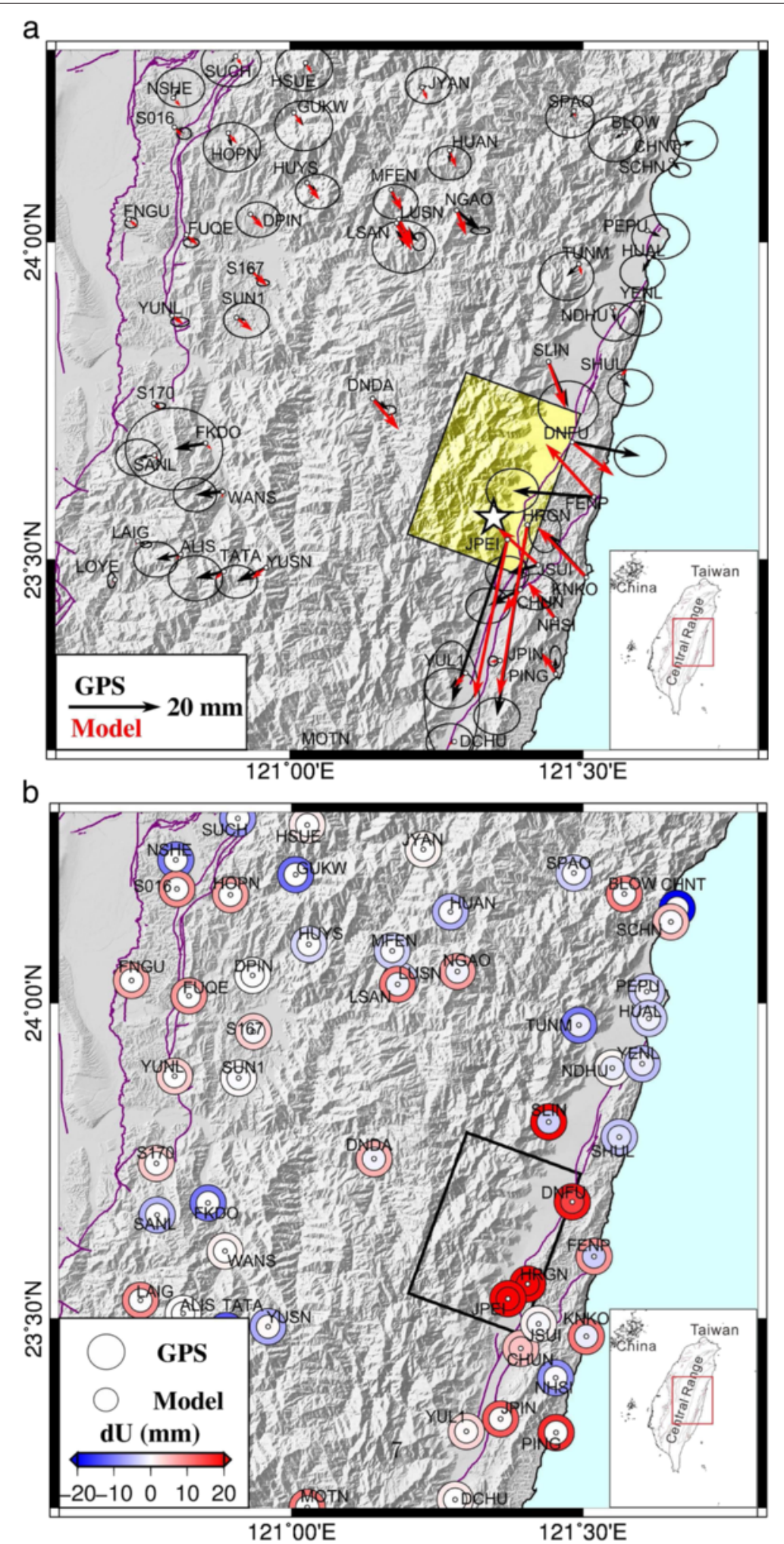

Fig. 2 Co-seismic GPS displacements and coseismic slip during the $2013 M_{w} 6.2$ Ruisui earthquake. The black and red arrows denote the observed and predicted displacements respectively (a horizontal components, $\mathbf{b}$ vertical component). The mean slip inferred from the best fit of GPS displacements is about $0.096 \mathrm{~m}$ 
1990) and the 2004 Parkfield (Johnston et al. 2006) earthquakes. In central Italy, data from two laser strainmeters located at about $20 \mathrm{~km}$ NE of the epicenter of the $2009 M_{w}$ 6.3, L'Aquila earthquake (Amoruso and Crescentini 2010), provided constraints on the rupture process. Five borehole strainmeters have recorded with high signal-to-noise ratio co-seismic strain offsets of the 1987 M 5.8 Vatnafjöll in south Iceland. Their good azimuthal distribution (about $130^{\circ}$ ) allows tight constraints on the source models and thus provides maybe the best static dislocation model inferred from strainmeter data so far (Ágústsson et al. 1999).

In the present paper, we focus on relocating the $30 \times 30$ $\mathrm{km}^{2}$ Ruisui earthquake and estimating its source fault parameters through four co-seismic static volumetric strain offsets. We also search for any pre-seismic strain signal and assess the capability of very short-term prediction in the area during the earthquake.

\section{High-resolution borehole strain data}

The Institute of Earth Sciences Academia Sinica (IESAS) in cooperation with the Department of Terrestrial Magnetism, Carnegie Institution of Washington, has deployed since 2003, 11 Sacks-Evertson borehole strainmeters (8 SES-1, 3 SES-3 design, (Hsu et al. 2015)) at a depth range of 180-270 $\mathrm{m}$ along the active Longitudinal Valley fault in eastern Taiwan (Fig. 1). These sites have been established near Taroko, Ruisui-Chimei, and Chengkung-Chihshang areas in eastern Taiwan, with a main objective of detecting fault slip along the LVF and the CRF. Due to their short-period resolution (about $10^{-2} \mathrm{n} \epsilon$ ) and their high short-term stability $\left(10^{-2}-10^{3} \mathrm{~s}\right)$, borehole strainmeters can supply continuous GPS in a geodetic network, especially at short period (up to $10^{3}$ in resolution) and could also play a leading role in the attempt of tracking aseismic deformation prior to earthquakes. Furthermore, they are also useful for observing slow slip events occurring during the interseismic period on different tectonic settings (Linde et al. 1988, 1996) and also for retrieving earthquake source fault parameters through their accurate co-seismic static strain offsets (Wyatt 1988) or modeling the post-seismic deformation (Takanami et al. 2013). The instruments installed along the LVF are completing the few networks deployed worldwide; in particular in Japan (Okada et al. 2004), in western USA (Roeloffs 2010), or in western Europe (Bernard et al. 2006; Canitano et al. 2013, 2014, Crescentini et al. 1997), for instance. Dilatometers installed in eastern Taiwan have recorded tens of slow earthquakes between 2003 and 2007, and some of them were found to be triggering by typhoons (Hsu et al. 2015; Liu et al. 2009).

Here, we focus on the four stations located on the central LV (Hsu et al. 2015) between the cities of Ruisui and Chimei (Fig. 1) as they are located about $20-30 \mathrm{~km}$ from the epicenter of the 2013 Ruisui shock and open the possibility to pre-strain signatures (Takemoto 1991). Note that the instruments have been calibrated against the Earth tides $\left(M_{2}\right.$ constituent) by using the common technique of comparing output data with the modeled tidal signals. As a check on these calibrations, the responses of the stations have been compared to long-period (50 $-100 \mathrm{~s})$ surface waves from distant great earthquakes and a good agreement between the ratios of tidal and waveform admittances has been found (Hsu et al. 2015). The calibration of borehole strainmeters using the solid Earth tides (or surface waves) means that it includes local structures, somewhat similar to a station correction in seismology. So, in contrast with data that are "absolute" (e.g., as GPS for instance), the borehole data are corrected for local structures. Moreover the instrumental sensitivity of the strainmeter is frequency independent over the range of concern. For sites where the instrument is installed in competent rock (as in the present network), we have not seen any indication of a frequency dependence so far.

Relevant co-seismic offsets recorded at a high sample rate of $100 \mathrm{~Hz}$ during the first $8-10 \mathrm{~min}$ of the Ruisui earthquake are presented in Fig. 3 and listed in Table 1. Their amplitudes are estimated by comparing the strain levels, after the amplitude of the oscillatory wavemotion following the mainshock has decreased, to the strain level preceeding the mainshock (about 8-10 min after the initiation). Note that in the convention adopted here, expansion is positive and amplitudes are expressed in $\mathrm{n} \epsilon$ (nanostrain). The volumetric co-seismic offset recorded at each site indicates a contraction with the largest amplitude at HSGB site and much more moderate ones at SSNB and CHMB stations; whereas signal at ZANB dilatometer is extremely small. Moreover, the volumetric dynamic deformation associated with the S-wave exhibits a clear 5-s period pulse (Fig. 3, around $10 \mathrm{~s}$ ) associated with large peak-to-peak amplitude; about $1.7 \times 10^{4} \mathrm{n} \epsilon$ for HGSB, $1.2 \times 10^{4} \mathrm{n} \epsilon$ for SSNB, and $8 \times 10^{3} \mathrm{n} \epsilon$ for CHMB and ZANB stations, respectively.

\section{Preliminary GPS model GPS data}

The collected GPS data were processed with GAMIT10.42/ GLOBK5.16 software packages (Herring et al. 2010) using the double-differenced ionosphere-free carrier phase observations (L3) as the basic observables. To obtain a more accurate and consistent regional deformation pattern in Taiwan, we used continuous GPS data from 362 Taiwan sites, 8 Ryukyu sites, and 17 IGS sites in the Asia-Pacific region. Fourteen IGS sites with long observation history surrounding the study area are constrained to their 2005 International Terrestrial Reference Frame (ITRF2005) (Altamini et al. 2007) coordinates in GLOBK processing, together with the parameters from GAMIT 


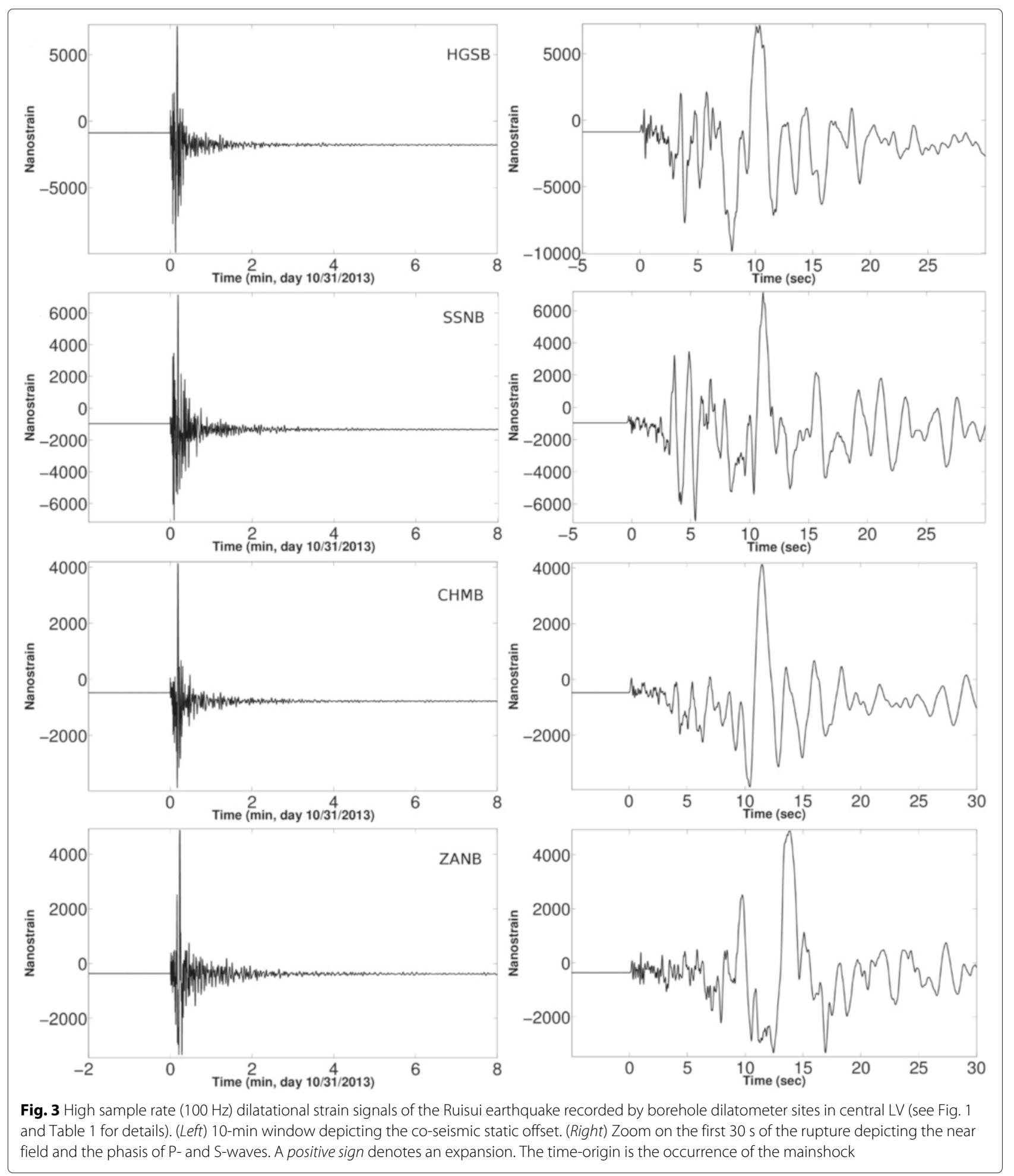

solutions to produced ITRF2005 coordinates of the other GPS sites. We performed a least squares linear fit to estimate the station velocity (linear rate), annual and semiannual periodic motions, post-seismic relaxation, and offsets caused by coseismic jumps and instrument changes from station position time series. The coseismic displacements of the Ruisui earthquake were estimated from the amplitude of the Heaviside step function at the time of the mainshock with the uncertainties of coseismic displacements calculated from the model covariance matrix. The 
Table 1 Observed and theoretical volumetric strain static offsets (in $n \epsilon$ )

\begin{tabular}{lllll}
\hline Sites & HGSB & SSNB & CHMB & ZANB \\
\hline Location (Lon-Lat) & $121.4237^{\circ}-23.4903^{\circ}$ & $121.3981^{\circ}-23.4423^{\circ}$ & $121.4703^{\circ}-23.4868^{\circ}$ & $121.4530^{\circ}-23.4062^{\circ}$ \\
Observed & -910 & -380 & -300 & -12 \\
Model (1) & 1310 & 784 & -1442 & -683 \\
Model (2) & -2214 & -1367 & -91 & 167 \\
Model (3) & -909 & -381 & -298 & -13 \\
\hline
\end{tabular}

(1) Source parameters from GPS inversion (strike $=200^{\circ}, \mathrm{dip}=45^{\circ}$, rake $\left.=42^{\circ}\right)$, (2) source parameters from seismology $\left(209^{\circ}, 59^{\circ}, 50^{\circ}\right)$, $(3)$ source $\mathrm{model}$ inferred from our best solution through a grid-search approach using co-seismic static strain offsets $\left(217^{\circ}, 48^{\circ}, 49^{\circ}\right)$. The slip is assumed to be $0.096 \mathrm{~m}$ on a $30 \mathrm{~km} \times 30 \mathrm{~km}$ fault plane. The center of the fault plane is located at $15 \mathrm{~km}$ depth at the position $\left(121.3694^{\circ} \mathrm{E}, 23.6033^{\circ} \mathrm{N}\right)$ for models (1) and (2) and at $15.5 \mathrm{~km}$ depth at the position $\left(121.3785^{\circ} \mathrm{E}, 23.6725^{\circ} \mathrm{N}\right)$ for model (3), respectively. A positive sign denotes an extension. Location of the sites (Longitude-Latitude) is also described

amplitudes of coseismic horizontal and vertical displacements in the rupture area are about 5-40 and -20-40 $\mathrm{mm}$, respectively (Fig. 2).

\section{Modeling of fault geometry and slip distribution}

We used GPS coseismic displacements and an elastic halfspace dislocation model (Okada 1985) to invert for the optimal fault geometry and the slip distribution of the Ruisui earthquake. We constrained the fault length and width to be $30 \mathrm{~km}$, according to the empirical source scaling relationship between earthquake magnitude and rupture width (Wells and Coppersmith 1994). We then search for other source fault parameters (strike, dip, fault top position) with different ranges based on a priori information from the mainshock focal mechanism. A weighted least-square inversion algorithm was employed to solve for coseismic slip distribution by minimizing the following functional:

$$
F(s, \beta, m)=\left\|\Sigma^{-1 / 2}(G(m) s-d)\right\|^{2}
$$

where $\Sigma^{-1 / 2}$ is the inverse square root of the data covariance matrix; $G(m)$ are Green's functions in an elastic half-space (Okada 1985), which depends on the fault parameters $m$; $s$ is the slip; and $d$ is the observed displacements. We estimated the reduced chi-square $\chi_{r}^{2}$ to evaluate the goodness of the fit. A good fit is achieved with the value of $\chi_{r}^{2}$ about 1 , meaning that the fault model fits data within uncertainties. We adopted a grid searching approach to find the optimal solution of the fault parameters. We varied fault strike from $190^{\circ}$ to $230^{\circ}$, depths of fault top from 0 to $10 \mathrm{~km}$, fault dip from $40^{\circ}$ to $70^{\circ}$ and fault position from $\pm 10 \mathrm{~km}$ of the epicenter location. Our preferred fault model exhibits $65 \mathrm{~mm}$ of reverse slip and $72 \mathrm{~mm}$ of left-lateral slip on a $\mathrm{N} 200^{\circ}$-trending fault with $\operatorname{dip} 45^{\circ}$ to NW (Fig. 2).

\section{Source parameters of the Ruisui earthquake inferred from co-seismic strain data Modeling with pre-existing source parameters}

In a first step, we propose to model the dilatational coseismic offset at each strainmeter site in the case of the two source parameters already determined (see the "Introduction" section and Table 1 for details). We model the Ruisui source as a rectangular plane of $30 \mathrm{~km} \times$ $30 \mathrm{~km}$ with a uniform slip of about $0.096 \mathrm{~m}$ inferred from the best model inverted from GPS data (see the 'Preliminary GPS model' section for the details). In both cases, the source is located at a depth of about $15 \mathrm{~km}$ and the rigidity of the medium is set up to $30 \mathrm{GPa}$, thus leading to a seismic moment of about $2.6 \times 10^{18}$ N.m or equivalently a $M_{w}$ of about 6.2. We use Okada's (Okada 1992) formulation for the internal deformation due to a dislocation embedded in homogeneous elastic half-space. The study of the P-wave tomography shows an approximately homogeneous medium in the crust beneath the central part of the Central Range (P-wave velocity ranging from $5.5-6.5 \mathrm{~km} . \mathrm{s}^{-1}$ at depths of 5-25 km) (Kuo-chen et al. 2012).

The predicted co-seismic strain offsets based on different fault models are presented on Fig. 4 and listed in Table 1. The co-seismic model resulting from GPS inversion (model (1)) gives signs opposite to the observed signals at HGSB and SSNB sites and amplitudes larger than the observations by about $50 \%$ (see Fig. 4a and Table 1). At CHMB and ZANB sites, the amplitudes are much too large. Strain amplitudes calculated from the model based on long-period seismic waveform inversion (model (2)) are different from observations at HGSB and SSNB by a factor of 3 to 4 (see Fig. $4 \mathrm{~b}$ and Table 1), whereas they differ from a factor of 3 for $C H M B$. Moreover, the sign of predicted strain at ZANB is opposite from the observation (contraction) and the predicted amplitude is too large. Therefore, in the next section, we take advantage of the station sensitivity to the azimuthal change in addition to the small amplitude recorded at ZANB (which has to be located most likely close to a nodal plane) to relocate the source position and invert for optimal fault parameters.

\section{Exploring the source parameters through a strain data inversion}

We decide to use initial constraints of the fault size and the total slip resulting from GPS inversions (i.e., $30 \mathrm{~km} \times$ 

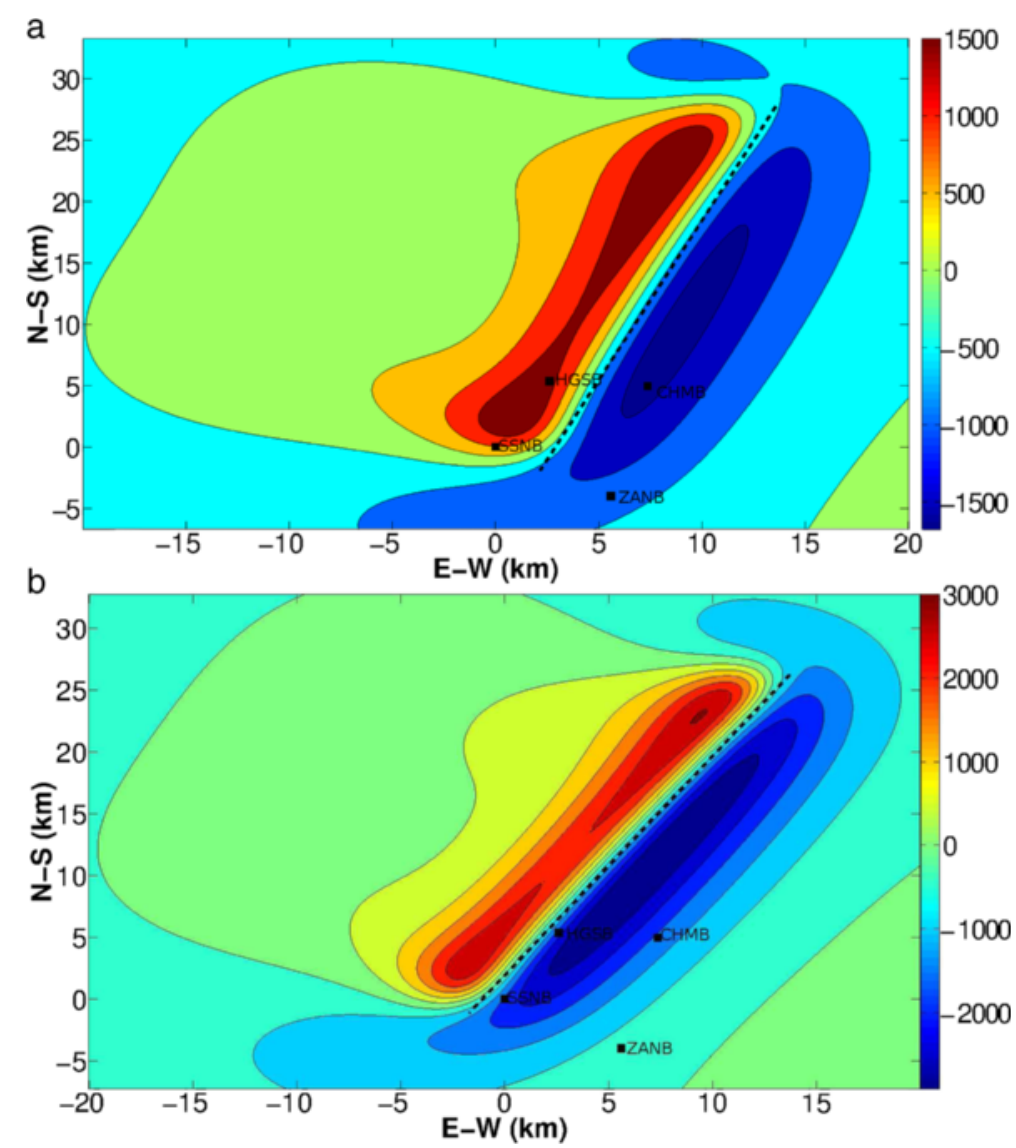

Fig. 4 Dilatational co-seismic static offsets of the Ruisui earthquake on the central borehole dilatometer site predicted by source models from GPS and seismic data, respectively. a Source parameters inferred from GPS inversion. b Source parameters from seismology $\left(209^{\circ}, 59^{\circ}, 50^{\circ}\right)$. The reference is the location of the SSNB strainmeter. Strain field is estimated at a mean depth of $200 \mathrm{~m}$. The right colorbar indicates the amplitude in $\mathrm{n} \epsilon$ and positive value is an expansion. The dashed black line roughly denotes the surface projection of the fault

$30 \mathrm{~km}$ with a uniform slip of $0.096 \mathrm{~m}$, equivalent to a $M_{w}$ 6.2 earthquake). We search for both source parameters (strike, dip, rake) and source position by using a grid-point search to find the best fit to the co-seismic static offsets. We investigate the centroid position by varying its location along a grid of $40 \mathrm{~km} \times 40 \mathrm{~km}$ while fault strike, dip, and rake are varying along their usual ranges (e.g., $0^{\circ}-360^{\circ}$, $0^{\circ}-90^{\circ},-180^{\circ}-180^{\circ}$, respectively).

An excellent fit is achieved through a grid-search approach by translating the initial dislocation fault plane inferred from GPS/seismology inversion by about $7 \mathrm{~km}$ to north and $1 \mathrm{~km}$ to east directions respectively with strike, dip and rake angles of $217^{\circ}, 48^{\circ}$ and $49^{\circ}$, respectively (see Fig. 5a). The fault plane resulting from our best model is located from $4.35 \mathrm{~km}$ to $26.65 \mathrm{~km}$ in depth. These parameters $\left(217^{\circ}, 48^{\circ}\right.$ and $\left.49^{\circ}\right)$ are reasonably close to those inferred from the inversions of long-period seismic waves $\left(209^{\circ}, 59^{\circ}, 50^{\circ}\right)$ and of GPS data $\left(200^{\circ}, 45^{\circ}, 42^{\circ}\right)$. The main difference is in the fault position which is moved of about $7 \mathrm{~km}$ to the direction of $\mathrm{N} 37^{\circ} \mathrm{E}$ and the fault depth moved about 1 and $2 \mathrm{~km}$ deeper compared to the fault planes inferred from seismic and GPS data respectively (see Fig. 5b).

Predicted GPS displacements using the fault model based on strain data $\left(217^{\circ}, 48^{\circ}, 49^{\circ}\right)$ are shown in Fig. 6. The far-field horizontal displacements for both models are similar, showing a SE motion (see for instance stations MFEN, NGAO, LUSN, or LSAN on on Fig. 6a and Fig. 2a). The horizontal displacements for GPS stations along the east coast, near the dilatometer sites, are also similar for both models, indicating a global NW motion (stations KNKO, NHSI, or PING). To the north, the southerly motion of stations NDHU, YENL, or HUAL are well fit by the source determined from strainmeter data whereas the inversion using GPS data gives very small displacements. The largest discrepancy in the source models inverted by GPS and strain data are in the near-field horizontal displacements. If the SE motion at SLIN is well constrained by both models, the source from GPS allows to strongly constrain the S-SW displacements at stations JPEI and HRGN (see Fig. 6a and Fig. 2a). The estimation of the average misfits calculated by the use of the GPS stations 


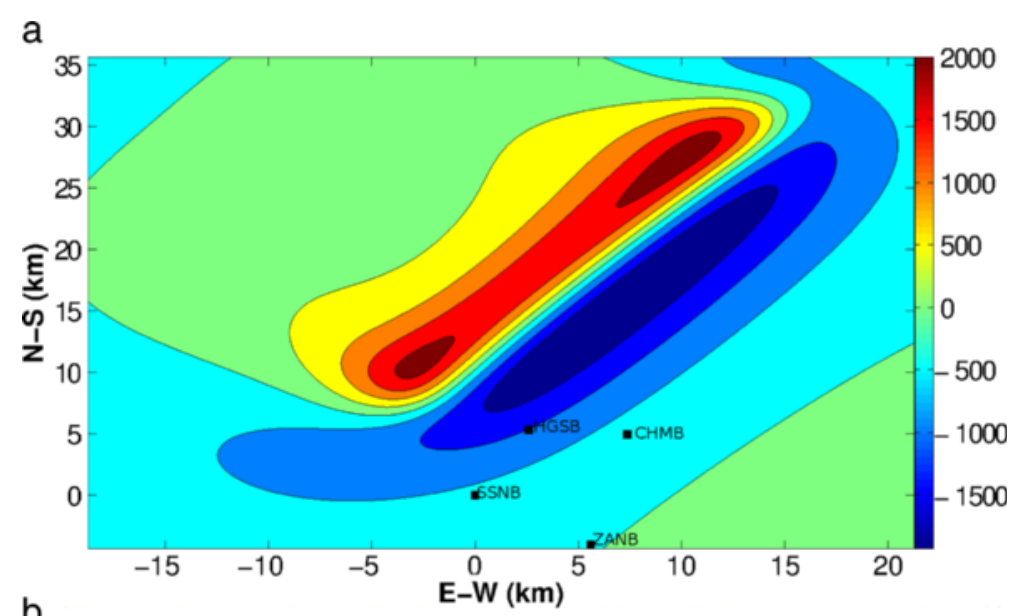

b

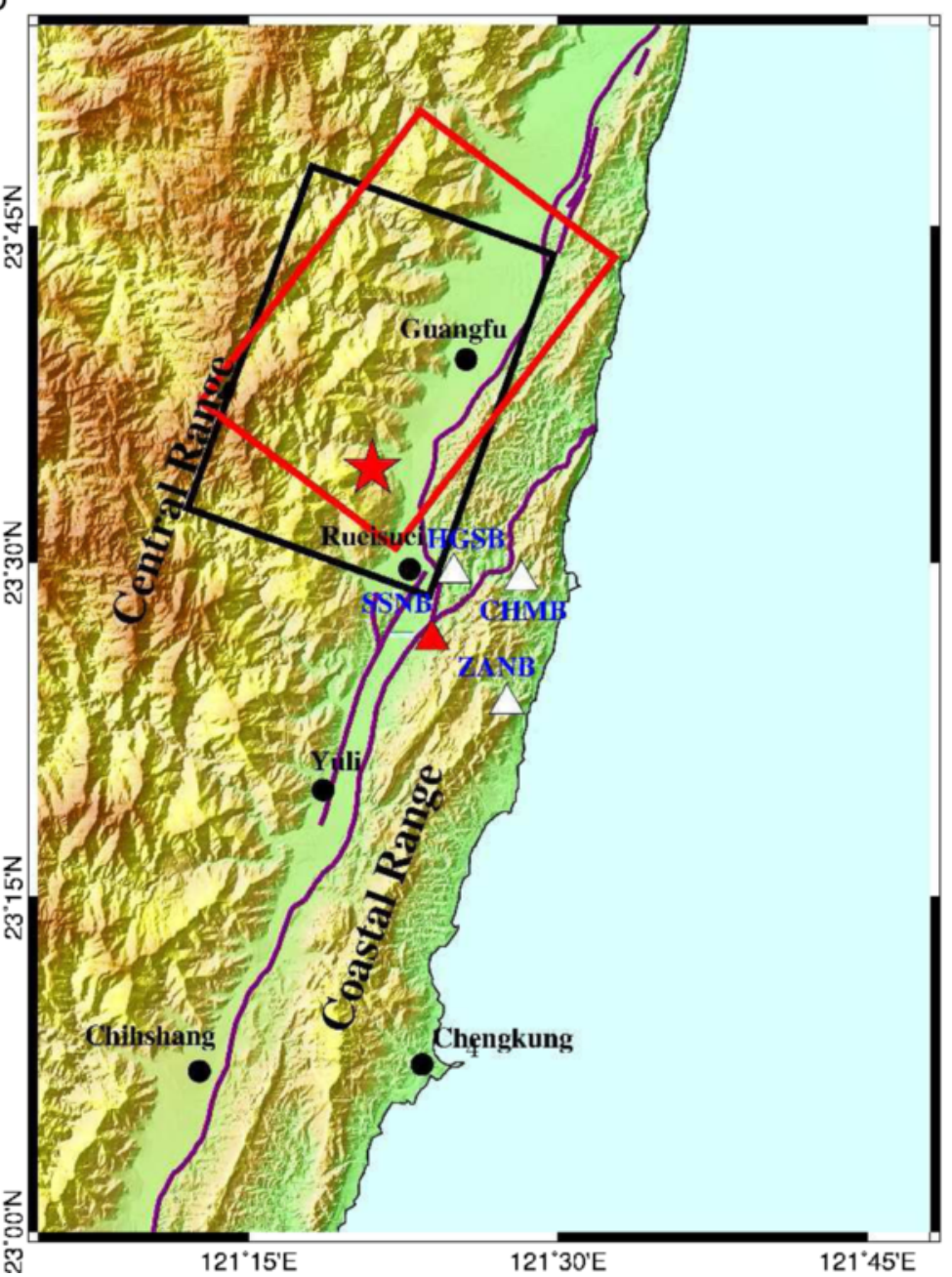

Fig. 5 Best source model inferred by strainmeter data using a grid search (see Table 1, Model (3) for details). The center of our best model is located at the position $\left(121.3785^{\circ} \mathrm{E}, 23.6725^{\circ} \mathrm{N}\right)$ and the depth extends from 4.35 to $26.65 \mathrm{~km}$. The strike, dip and rake angles are $217^{\circ}, 48^{\circ}$ and $49^{\circ}$, respectively. The black rectangles label the borehole dilatometer sites. b Map of the fault planes inverted using GPS data (black) and strainmeter data (red) (see Fig. 1 for details). The red star denotes the epicenter location from CWB

located in the near-to-intermediate field of the earthquake (23 stations in a radius of about $50 \mathrm{~km}$ around the epicenter) gives a value of $5.3 \mathrm{~mm}$ when using the fault model obtained from GPS inversion and of $6.9 \mathrm{~mm}$ with the model obtained by strain data inversion. This difference confirms the discrepancy between both prediction 


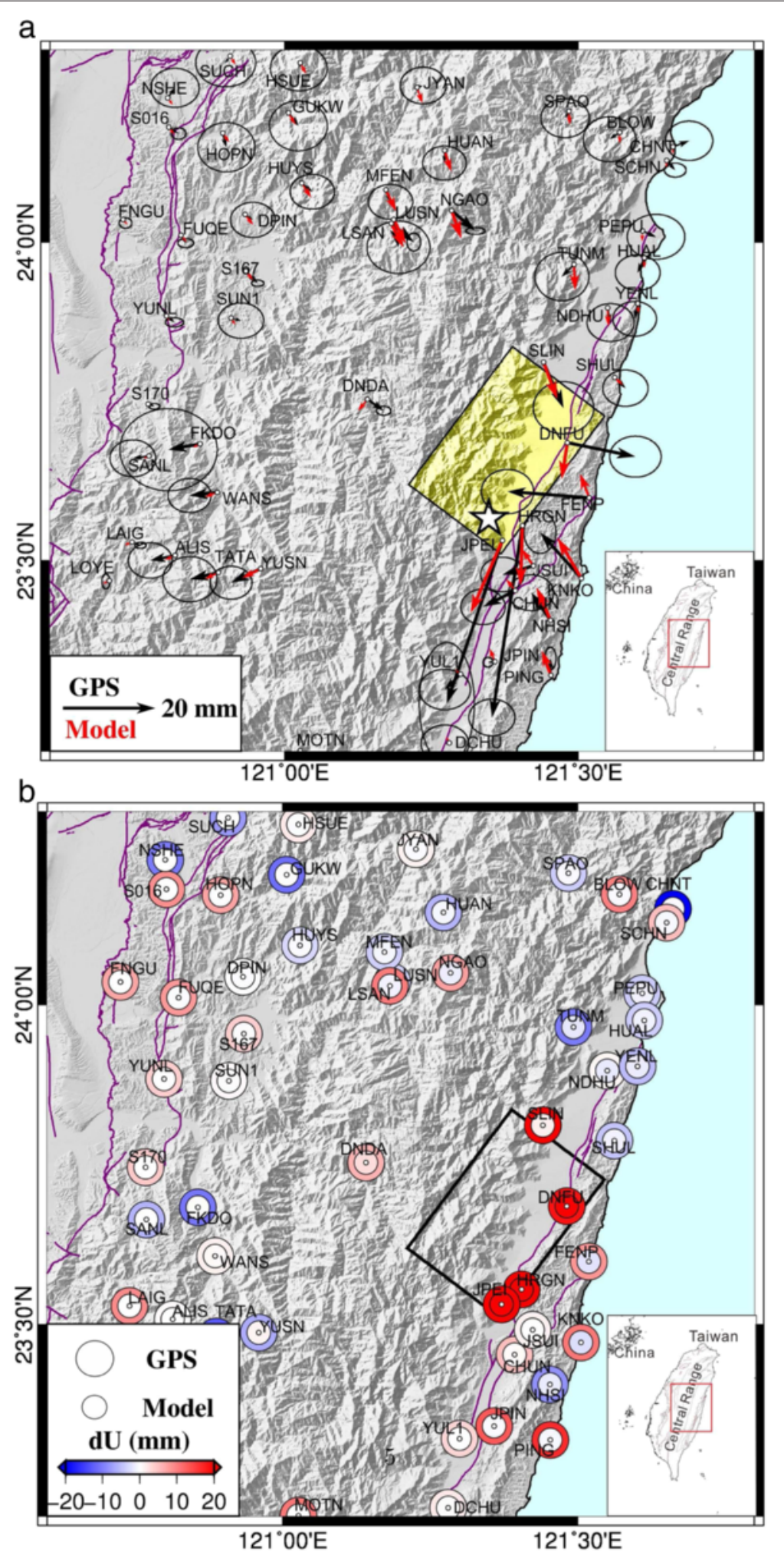

Fig. 6 Co-seismic GPS displacements during the $2013 M_{w} 6.2$ Ruisui earthquake. The black and red arrows denote the observed and the predicted displacements by the source resulting from the inversion of the strainmeter data (a horizontal components, $\mathbf{b}$ vertical component) 
in the near field of the earthquake. The prediction of the near-field vertical displacements are quite consistent at JPEI and HRGN stations, main differences come from the amplitudes, slightly underestimated by strain data (see Fig. $6 \mathrm{~b}$ and Fig. 2b). The vertical displacement at DNFU, once again well fitted by GPS, is overstimated by a factor 2 with the strain model. Moreover, in the intermediate field, the vertical displacements remain poorly constrain as the vertical motions predicted by both models are too small and on the opposite direction (see stations SLIN and FENP in the vicinity of the fault plane for instance).

\section{Pre-seismic deformation in the near field of the Ruisui earthquake and limits of earthquake nucleation}

Searching for non-linear strain prior to a seismic rupture is of importance in the issue of precursory activity. We use these near-field measurements to look for any pre-seismic strain signature. Indeed, according to theory and laboratory experiments, accelerating strain resulting from increased deformational weakening occurs before the dynamic slip instability resulting in an earthquake (Dieterich 1994). To be linked to the nucleation at the earthquake hypocenter, the strain history should be exponential-like with the largest strain changes occurring at the last stage of failure and the amplitude or size of the strain change relating to the eventual earthquake moment release. Those studies gave hope for the earthquake prediction. Unfortunately, studies of continuous strain measurements of moderate to large earthquakes have not so far revealed any such exponentially increasing strain (Agnew and Wyatt 1989; Amoruso and Crescentini 2010; Johnston et al. 1990, 1994, 2006). This does not necessarily mean that accelerating strain is not occurring, only that if it occurs, it is below the measurement resolution. Thus, this lack of observations limits any nucleation zone to be small compared with the rupture size.

We present the $10 \mathrm{~s}$ of the recorded volumetric strain immediately preceding the arrival of seismic waves (Fig. 7a). The longest period oscillations of few $10^{-1} \mathrm{n} \epsilon$ in the data time series are the volumetric strain signatures of the microseisms (e.g., surface waves generated at sea) (Agnew 1986). The strongest effects (around $5 \times$ $10^{-1}-7 \times 10^{-1} \mathrm{n} \epsilon$ ) are the 2.2 and 3.7 s period microseisms on HGSB and SSNB signals, respectively. CHMB and ZANB sites are sensitive to most of them with a mean amplitude of about $3 \times 10^{-1}-5 \times 10^{-1} \mathrm{n} \epsilon$. In order to estimate the noise level (defined as the standard deviation here), we remove in a first order the main harmonics in the microseism band by band-pass filtering the signals in the range of 1-10 Hz (Fig. 6b). After a first-order correction of the energy in the main high-frequency microseism range, the noise reaches a maximum of about $10^{-1} \mathrm{n} \epsilon$ on HGSB signal whereas CHMB exhibits a noise level smaller by 1 order of magnitude (see Table 2 for details). No coherent exponential-like changes larger than few $10^{-2}$ to $10^{-1} \mathrm{n} \epsilon$ are apparent in the signals. Note that we limited our study to seconds before the mainshock as longer data time series are still perturbed by long-period microseisms (with energy at periods up to tens of seconds) and also by local atmospheric perturbations at periods ranging from 100 to $200 \mathrm{~s}$ for instance (see Fig. 8). Most of the barometric sensors have experienced some problems prior to the mainshock (except at ZANB site).

However, the lack of pre-seismic signals can put strength and size limits to the earthquake nucleation phase. In the first step, we calculated through Okada's formulation (Okada 1992) the maximum precursory slip moment that can be released over a period of seconds before seismic rupture by means of the noise level estimated at each site (see Table 2). We try two source models: the first (source S1, see Table 2) is the hypocenter location $\left(121.348^{\circ} \mathrm{E}, 23.566^{\circ} \mathrm{N}\right)$ and the source fault parameters inferred from seismology $\left(209^{\circ}, 59^{\circ}, 50^{\circ}\right)$ while the second (source $\mathrm{S} 2$ ) is the orthogonal projection of the hypocenter on the plane resulting from our global strain inversion (see red plane on Fig. 9a) combined by its own source fault parameters $\left(217^{\circ}, 48^{\circ}, 49^{\circ}\right)$. This hypothesis makes sense as the the latter is located at about $3 \mathrm{~km}$ from the plane located by seismology (Fig. 9) and may be subject to some incertitudes on its location. Furthermore, as the size of this hypothetical nucleation patch is arbitrary in a first time, as we are first interested in the maximal precursory slip moment at each of the four sites, we consider a $1 \mathrm{~km} \times 1 \mathrm{~km}$ patch surrounding each hypocenter location. We here assume a pre-seismic strain signal to be clearly detectable if it reaches a minimal value of twice the standard deviation. Since the maximum precursory slip moment $M$ that can be released has been estimated for each site, it is also possible to access the maximal length of the nucleation zone $L$ in the last few seconds before the seismic radiation occurs by the following relation (Johnston and Linde 2002):

$$
M=\mu 10^{-4} L^{3}
$$

where $\mu$ is the rigidity ( $30 \mathrm{GPa}$ ). The maximum size of the nucleation zone differs from about 30-50 $\mathrm{m}$ from the two considered sources (see Table 2, sources (S1) and (S2)). The site CHMB, which exhibits the smaller noise level at very short period, may have been capable to track a change in an area with dimension of about $250-300 \mathrm{~m}$, seconds before seismic radiations occur. The related strength is about $5 \times 10^{13} \mathrm{~N}$.m which is about $10^{-5} \%$ of the total seismic moment of the Ruisui earthquake.

\section{Discussion}

The 2013 October $31 M_{w} 6.2$ Ruisui earthquake, on central LVF, occurred in the near field of a network of 

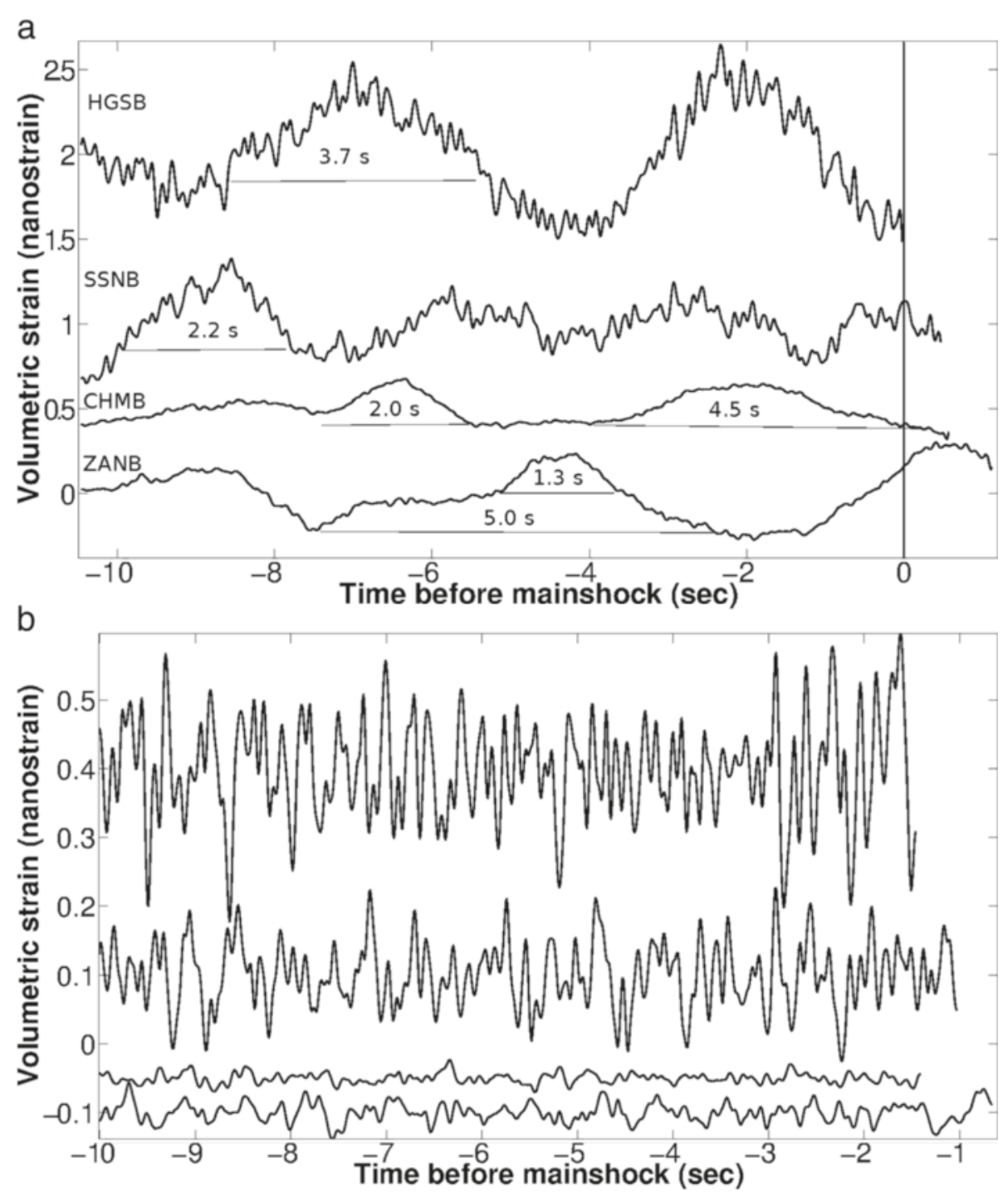

Fig. 7 Pre-seismic high-frequency volumetric strain recorded at the four strainmeter sites. a Last 10 s preceding the first $P$ arrival of low-pass filtered (high cut of $10 \mathrm{~Hz}$ ) and detrended strain signals. The depicted oscillations are the signatures of the microseisms (surface waves generated at sea). The vertical line denotes the first P arrival at HGSB station (origin of time). $\mathbf{b}$ Same signals detrended and pass-band filtered in the interval [1-10 Hz] to remove the microseism energy at the first order. Note that the last second before mainshock has been truncated for the plot because of high-pass filtering instability of the dynamic pulse associated to first P-wave arrival. The standard deviation $\sigma_{\epsilon}$ of each component is listed in Table 2. The traces have been shifted vertically for the plot

Table 2 Standard deviation $\left(\sigma_{\epsilon}\right)$ of strain signals recorded 10 s preceding the arrival of the first P-waves, estimated slip, maximal nucleation moment, and maximal length of the nucleation zone in the case of the sources (S1) and (S2)

\begin{tabular}{lllll}
\hline & HGSB & SSNB & CHMB & ZANB \\
\hline Standard deviation $\sigma_{\epsilon}(\mathrm{n} \epsilon)$ & $10^{-1}$ & $5 \times 10^{-2}$ & $10^{-2}$ & $2 \times 10^{-2}$ \\
(S1) Maximal moment (N.m) (slip, in m) & $3.6 \times 10^{14}$ & $3 \times 10^{14}$ & $4.8 \times 10^{13}$ & $2.4 \times 10^{14}$ \\
Maximal slip (in m) & $12 \times 10^{-3}$ & $10 \times 10^{-3}$ & $1.6 \times 10^{-3}$ & $8 \times 10^{-3}$ \\
Maximal nucleation length (m) & 490 & 465 & 250 & 430 \\
(S2) Maximal moment (N.m) (slip, in m) & $4.5 \times 10^{14}$ & $3.3 \times 10^{14}$ & $8.1 \times 10^{13}$ & $3 \times 10^{14}$ \\
Maximal moment (N.m) & $15 \times 10^{-3}$ & $11 \times 10^{-3}$ & $2.7 \times 10^{-3}$ & $10 \times 10^{-3}$ \\
Maximal nucleation length (m) & 530 & 480 & 300 & 465 \\
\hline
\end{tabular}




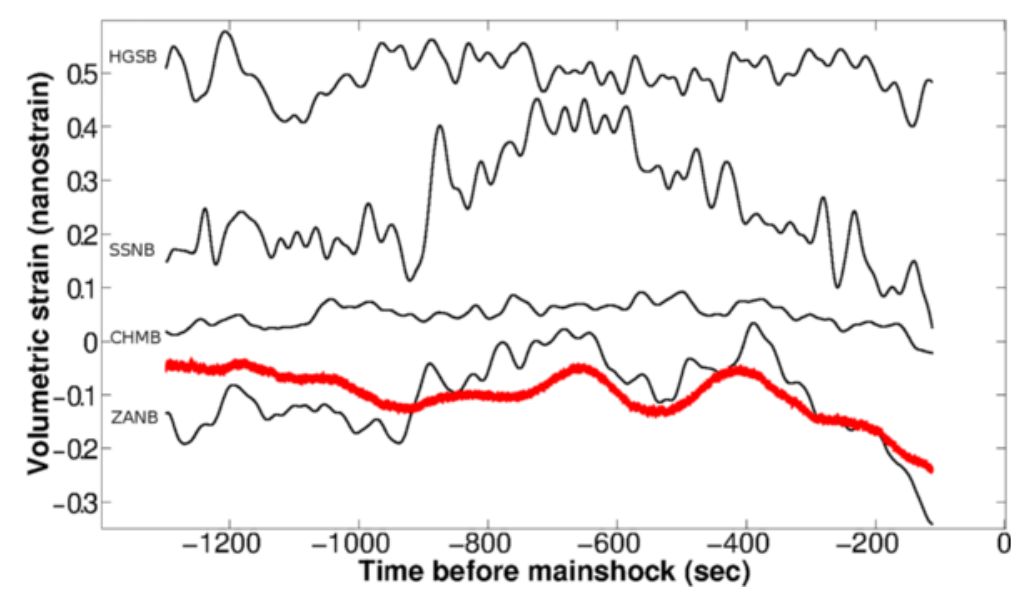

Fig. 8 Volumetric strain signals 20-min preceding the Ruisui earthquake. Signal have been low-passed at 30-s period to remove the main periods of microseisms. The traces have been shifted vertically for the plot, and the stations are named accordingly. The red signal is the atmospheric pressure (in mbar) recorded at ZANB site
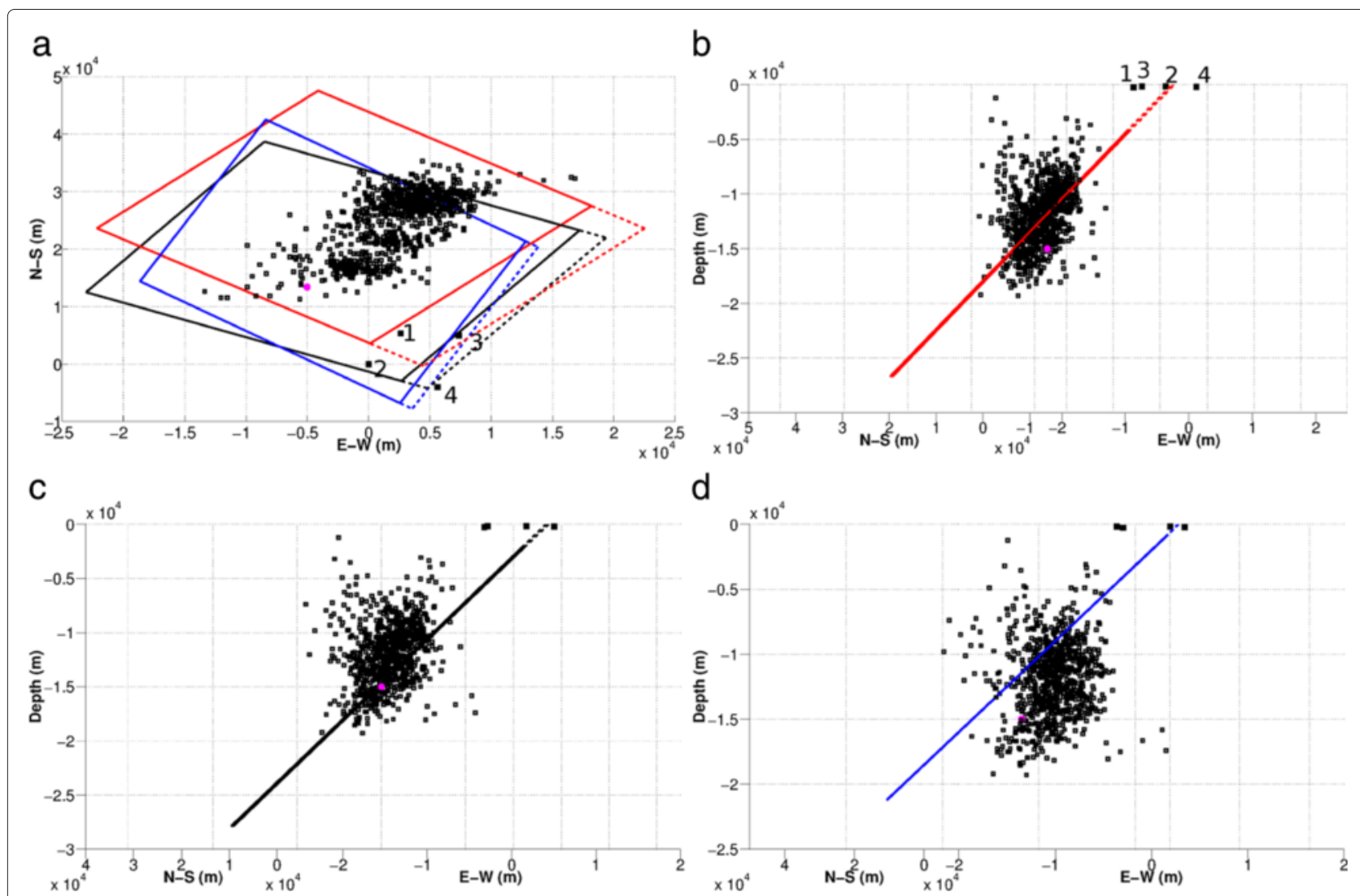

Fig. 9 a Surface projection of the fault planes of the $M_{W} 6.2$ Ruisui earthquake (solid line) inverted from long-period surface waves (Lee et al. 2014) (black), from GPS inversion (b/ue), and from strain data inversion (red). The dotted line denotes the extension of each fault plane through the surface The magenta dot localizes the hypocenter from CWB $\left(121.348^{\circ} \mathrm{E}, 23.566^{\circ} \mathrm{N}\right)$, the thin black squares denote the first 5 days of relocated aftershocks, and the large black squares denote the strainmeter sites (1 HGSB, 2 SSNB, 3 CHMB, 4 ZANB). b-d 3D view of the faults planes showing the relocated aftershocks with the fault plane inferred from strain (red), seismology (black), and GPS (blue) inversions, respectively. The distribution of aftershocks exhibits three swarms, the largest (more than $50 \%$ of the events) on the northeast and two similar swarms located at few kilometers southwest and arranged along a line striking at about $210-215^{\circ}$. They cover an overall area of about $15-20 \mathrm{~km}$ E-W and N-S 
Sacks-Evertson borehole dilatometers. We performed a grid search for the best fit to the co-seismic static strain offsets and retrieved source fault parameters (strike $=$ $217^{\circ}$, dip $=48^{\circ}$, rake $=49^{\circ}$ ) in reasonable agreement with those from the inversions of long-period seismic waves $\left(209^{\circ}, 59^{\circ}, 50^{\circ}\right)$ as well as from GPS data $\left(200^{\circ}, 45^{\circ}, 42^{\circ}\right)$. The fault plane inferred from our best model based on strain data is located at depths of $4.35-26.65 \mathrm{~km}$, and fault position is moved of about $7 \mathrm{~km}$ to a $\mathrm{N} 37^{\circ} \mathrm{E}$ direction compared to the one inferred from previous study (Lee et al. 2014). Furthermore, further studies may consider the high-resolution near-field dynamic records in order to model the entire strain field and especially the high strain amplitude of 5-s period S-wave (see Fig. 3). This may give additional information about the rupture process, which has already been determined by the seismic waveform inversion (Lee et al. 2014).

Even if the seismic source resulting from this study do not exhibit large differences nor in the source mechanism neither in the position (see Fig. 5b), some non-negligible discrepancies appear on the predicted GPS displacements resulting from these two different geodetic instruments, especially in the near field (see Fig. 6 and Fig. 2). One may eventually result from the coverage of stations; indeed, there are about ten GPS stations in the near field of the Ruisui source with an azimuthal extension of about $180^{\circ}$ (from station SLIN in north to JPEI in south, see Fig. 6) when only four strainmeter stations are deployed in an azimuthal coverage of about $60^{\circ}$ with respect to the seismic source (see Fig. 5). We notice that the best constrained GPS displacements through the fault plane inferred from strain data inversion are the ones located in the azimuthal coverage of the strainmeter sites (e.g., stations KNKO, NHSI, or even PING, see Fig. 6a). In addition to this lack of resolution for strain data comparing to GPS data, some other parameters may explain the discrepancies revealed by the modelization of the GPS displacements. One may infer from the hypothesis of a uniform slip over a rectangular fault model which is a very simplified picture, and thus, strong differences may infer from sites close (in the near field to the fault plane. Moreover, even if strain data resolution is larger than GPS observations at a short period, some strong shacking on the source region may produce non-linear effects in the near-field strain which may especially be large on shear components $\left(\gamma_{1}\right.$ and $\left.\gamma_{2}\right)$. However, even though the dilatation is a very robust observation for co-seismic static strain offset, we cannot rule out an eventual non-linear effect perturbing these near-field strain measurements.

However, some robust constraints may arise from high-resolution strainmeter data. The case of the $M 5.8$ Vatnafjöll earthquake in south Iceland is a good example of a seismic source estimation through co-seismic static offsets which agrees very well with the seismic solutions
(Ágústsson et al. 1999). In general, dilatometers are more sensitive than cGPS data in determining the source depth. Indeed, buried sources result in dilatations that change sign at distances strongly dependent on the source depth (e.g., see nodal lines in solution plots on Figs. 4 and 5); thus, even with a few sites, we are able to add rather robust constraints on the source location and geometry. In the present study, the data recorded at the four sites deployed at the southeastern termination of the Ruisui fault plane in central LV allow to put robust constraints on the seismic source of the Ruisui earthquake. For instance, the upper limit of the fault plane (estimated at about 4.3 $\mathrm{km}$ depth) is very well constrained as an increase of less than $500 \mathrm{~m}$ would corrupt the sign at ZANB site (from compression to extension) which has to be located near a nodal line. Moreover, a change of $\pm 500 \mathrm{~m}$ on the depth of the plane would result on a change of about 5 to 20 $\%$ between HGSN/SSNB and CHMB sites with a constant sign. Besides, the ZANB site also enables to put an upper limit on the strike angle; a value larger than $219^{\circ}$ would change again its dilatation sign. The dip angle is also well constrained by the model, an upper limit (about $50^{\circ}$ ) is achieved through the observation at ZANB site again. The rake angle is less well constrained by most of the sites (a change of $5^{\circ}$ would result on an amplitude change of about $5-10 \%$ at HGSB, SSNB, and CHMB) while the difference is larger at ZANB (about $40 \%$ ). However, the inferred rake angle is similar to this resulting from the long-period waveform inversions (Lee et al. 2014). Furthermore, most of the aftershocks of the Ruisui earthquake are located at the depth range of about 6$18 \mathrm{~km}$ as illustrated by the relocation of events occurred over the five first days (about 800 events, see Fig. 9). The fault plane inferred from the strain data inversion encompasses almost all of the aftershocks when the fault planes inferred from seismology and GPS inversions encompass about $90-95 \%$ and $80-85 \%$ of these events, respectively (see Fig. 9). These differences seem to come especially from their horizontal position whereas both plane encompass most of the aftershocks at depths. The fault plane and the source mechanism from seismology, which presents the largest dip angle $\left(59^{\circ}\right.$, see Lee et al. (2014)), allow to follow very well the spatital evolution of the seismicity (Fig. 9c). Among seismic source mechanisms and locations through geodetic techniques, the one inferred from strain data (with a dip of $48^{\circ}$ ) allows to follow on a reasonable way the spatial distribution of aftershocks when the one inferred from GPS inversion may require a slightly larger dip. Finally, the location of the fault plane and the source fault parameters are in good agreement with the geology of the CRF as well as with the local tectonics.

The observations conducted on the $10 \mathrm{~s}$ previous to the initiation of the seismic rupture in the aim to search 
for an eventual pre-strain signature were found to be unsuccessful. Indeed, no exponential-like pre-strain signal was apparent, at least with amplitude larger than the noise level of the signals corrected at the first order from the microseismic effects (e.g., from $10^{-2}$ to $10^{-1} \mathrm{n} \epsilon$, see Fig. 7b). However, we may not rule out that accelerating strain is not occurring, only that it may occur below our measurement resolution or may have eventually been removed by our first-order microseism correction. The maximum size of the nucleation patch in the last few seconds before the mainshock which can be observed by the most favorable site (e.g., with the smaller noise level, CHMB) is about 250-300 m with associated strength of about $10^{-5} \%$ of the total seismic moment of the Ruisui earthquake. Furthermore, as the measurement noise is increasing with period (Crescentini et al. 1997), this estimation would be the maximal theoretical limit of our capability to track for a pre-seismic strain change in the near field of the $M_{w} 6.2$ Ruisui earthquake, irrespective of the period of observation. Any search for longer duration pre-seismic strain changes is complicated by the need to determine and remove spurious environmental effects (e.g., mostly due to barometric changes and precipitation).

\section{Conclusions}

We obtained reliable constraints on the source fault of the $2013 M_{w} 6.2$ Ruisui earthquake, in central CRF, through the inversion of few observations of borehole strainmeter co-seismic static strain offsets. Even though the inferred source location and parameters are presumably less well constrained compared to a global geodetic inversion (GPS and strainmeters) or even a joint one (by adding the seismic waveforms to the geodetic observations), the result is in good agreement with the previous analysis and also with the regional tectonic stress regime of the northeast-southwest west-dipping Central Range Fault. Furthermore, the Ruisui event may have ruptured the 25-30-km-wide transition zone between towns of Ruisui and Guangfu (see Fig. 5b) where no evidence of activity of the Central Range Fault had been reported by recent studies (Peyret et al. 2011; Shyu et al. 2005).

\section{Competing interests}

The authors declare that they have no competing interests.

\section{Authors' contributions}

AC performed the strainmeter data analysis, YJH performed the GPS inversion and helped to improve the manuscript. HML collected the strainmeter data. ATL and SS helped to improve the strain analysis and the manuscript. All authors read and approved the final manuscript.

\section{Acknowledgments}

We thank the editor Yosuke Aoki and the two anonymous reviewers that helped to improve the manuscript. We are grateful to many colleagues at the Institute of Earth Sciences, Academia Sinica who have participated in collecting strainmeter data. We thank Y. G. Huang for preparing the figures in the manuscript and Dr. S.-J. Lee for providing the aftershock location. Some figures were drawn using the software package GMT v3.4 (Wessel and Smith 1998). The authors thank Olaf Zielke for the availability of a free Matlab version of Okada 92 and valuable help concerning some aspects of the code. This study was supported by the Institute of Earth Sciences, Academia Sinica, the Ministry of Science and Techonolgy of the Republic of China grant NSC 101-2116-M-001-026-MY3.

\section{Author details}

1 Institute of Earth Sciences, Academia Sinica, P.O. Box 1-55, Nankang, Taipei, Taiwan. ${ }^{2}$ Department of Terrestrial Magnetism, Carnegie Institution of Washington, Washington, DC, USA.

Received: 10 May 2015 Accepted: 29 June 2015

Published online: 07 August 2015

\section{References}

Agnew DC (1986) Strainmeters and tiltmeters. Rev Geophys 24:579-624 Agnew DC, Wyatt FK (1989) The 1987 Superstition Hills earthquake sequence: Strains and tilts at Pinon Flat observatory. Bull Seism Soc Am 79(2):480-492 Ágústsson K, Linde AT, Stefánsson R, Sacks S (1999) Strain changes for the 1987 Vatnafjöll earthquake in south Iceland and possible magmatic triggering. J Geophys Res 104(B1):1151-1161

Altamini Z, Collilieux X, Legrand J, Garayt B, Boucher C (2007) ITRF2005: A new release of the International Terrestrial Reference Frame based on time series of station positions and Earth Orientation Parameters. J Geophys Res 112:B09401. doi:10.1029/2007JB004949

Amoruso A, Crescentini L (2010) Limits on earthquake nucleation and other pre-seismic phenomena from continuous strain in the near-field of the 2009 I'Aquila earthquake. Geophys Res Lett 37:L10307

Barrier E, Angelier J (1986) Active collision in eastern Taiwan: the Coastal Range. Tectonophysics 125:39-72

Bernard P, Lyon-Caen H, Briole P, Deschamps A, Boudin F, Makropoulos K, Papadimitriou P, Lemeille F, Patau G, Billiris H, Paradissis D, Papazissi K, Castarède H, Charade O, Nercessian A, Avallone A, Pacchiani F, Zahradnik J, Sacks S, Linde A (2006) Seismicity, deformation and seismic hazard in the western rift of Corinth: New insights from the Corinth Rift Laboratory (CRL). Tectonophysics 426:7-30

Biq C (1965) The East Taiwan Rift. Pet Geol Taiwan 4:93-106

Chai BH (1972) Structure and tectonic evolution of Taiwan. Am J Sci 272:383-432

Canitano A, Bernard P, Linde AT, Sacks S (2013) Analysis of signals of a borehole strainmeter in the western rift of Corinth, Greece. J Geod Sci 3:63-76

Canitano A, Bernard P, Linde AT, Sacks S, Boudin F (2014) Correcting high-resolution borehole strainmeter data from complex external influences and partial-solid coupling: the case of Trizonia, Rift of Corinth (Greece). Pure Appl Geophys 171(8):1759-1790

Chuang RY, Johnson KM, Wu YM, Ching KE, L C Kuo (2013) A midcrustal ramp-fault structure beneath the Taiwan tectonic wedge illuminated by the 2013 Nantou earthquake series. Geophys Res Lett 40. doi:10.1002/grl.51005

Crescentini L, Amoruso A, Fiocco G, Visconti G (1997) Installation of a high-sensitivity laser strainmeter in a tunnel in central Italy. Rev Sci Instru 68:887-905

Dieterich JH (1994) A constitutive law for rate of earthquake production and its application to earthquake clustering. J Geophys Res 99(B2):2601-2618

Herring T, King W, McCluskey SM (2010) Introduction to GAMIT/GLOBK release 10.4. Mass Inst of Technol, Cambridge

Hsu YJ, Chang YS, Liu CC, Lee HM, Linde AT, Sacks S, Chen Y (2015) Revisiting borehole strain, typhoons and slow earthquakes using quantitative estimates of precipitation induced strain changes. J Geophys Res 120(6):4556-4571. doi:10.1002/2014JB011807

Johnston MJS, Linde AT, Gladwin MT (1990). Near-field high resolution strain measurements prior to the October 18, 1989, Loma Prieta Ms 7.1 earthquake. Geophys Res Lett 17:1777-1780

Johnston MJS, Linde AT, Agnew DC (1994) Continuous borehole strain in the San Andreas fault zone before, during, and after the 28 June 1992, Mw 7.3 Landers, California, earthquake. Bull Seism Soc Am 96(3):799-805

Johnston MJS, Linde AT (2002) Implications of crustal strain during conventional, slow, and silent earthquakes. International Geophysics Series $81(A): 589-606$ 
Johnston MJS, Borcherdt RD, Linde AT, Gladwin MT (2006) Continuous borehole strain and pore pressure in the near field of the 28 September 2004 M 6.0 Parkfield, California, earthquake: Implications for nucleation, fault response, earthquake prediction, and tremor. Bull Seism Soc Am 96:S56-S72

Kuo-chen H, Wu FT, Roecker SW (2012) Three-dimensional P velocity structures of the lithosphere beneath Taiwan from the analysis of TAIGER and related seismic data sets. J Geophys Res 117:B06306. doi:10.1029/2011JB009108

Lee SJ, Huang HH, Shyu JBH, Yeh TY, Lin TC (2014) Numerical earthquake model of the 31 October 2013 Ruisui, Taiwan, earthquake: Source rupture process and seismic wave propagation. J Asian Earth Sci 96:374-385

Linde AT, Suyehiro K, Miura S, Sacks IS, Takagi A (1988) Episodic aseismic earthquake precursors. Nature 334:513-515

Linde AT, Johnston MJS (1989) Source parameters of the October 1, 1987 Whittier Narrows earthquake, from crustal deformation data. J Geophys Res 94(B7):9633-9643

Linde AT, Gladwin MT, Johnston MJS, Gwyther RL, Bilham RG (1996) A slow earthquake sequence on the San Andreas fault. Nature 383:65-58

Liu CC, Linde AT, Sacks IS (2009) Slow earthquakes triggered by typhoons. Nature 459:833-836

Okada Y (1985) Surface deformation due to shear and tensile faults in a half-space. Bull Seism Soc Am 75(4):1135-1154

Okada, Y (1992) Internal deformation due to shear and tensile faults in a half-space. Bull Seism Soc Am 82(2):1018-1040

Okada Y, Kasahara K, Hori S, Obara K, Sekiguchi S, Fujiwara H, Yamamoto A (2004) Recent progress of seismic observation neworks in Japan - Hi-net, F-net, K-NET and KiK-net. Earth Planets Space 56:xv-xxviii

Peyret M, Dominguez S, Cattin R, Champenois J, Leroy M, Zajac A (2011) Present-day interseismic surface deformation along the Longitudinal Valley, eastern Taiwan, from a PS-InSAR analysis of the ERS satellite archives. J Geophys Res 116:B03402. doi:10.1029/2010JB007898

Roeloffs EA (2010) Tidal calibration of Plate Boundary Observatory borehole strainmeters: Roles of vertical and shear coupling. J Geophys Res 115:B06405. doi:10.1029/2009JB006407

Sacks S, Suyehiro S, Evertson DW, Yamagishi Y (1971) Sacks-Evertson strainmeter, its installation in Japan and some preliminary results concerning strain steps. Pap Meteorol Geophys 22:195-208

Shyu JBH, Sieh K, Chen YG, Liu CS (2005) Neotectonic architecture of Taiwan and its implications for future large earthquakes. J Geophys Res 110:B08401. doi:10.1029/2004JB003251

Shyu JBH, Sieh K, Avouac JP, Chen WS, Chen YG (2006) Millennial slip rate of the Longitudinal Valley fault from river terraces: implications from convergence across the active suture of eastern Taiwan. J Geophys Res 111:B08403. doi:10.1029/2005JB003971

Takemoto S (1991) Some problems on detection of earthquake precursors by means of continuous monitoring of crustal strains and tilts. J Geophys Res 96(B6):10377-10390

Takanami T, Linde AT, Sacks SI, Kitagawa G, Peng H (2013) Modeling of the post-seismic slip of the 2003 Tokachi-oki earthquake M 8 off Hokkaido: Constraints from volumetric strain. Earth Planets Space 65:731-738

Wells DL, Coppersmith KJ (1994) New Empirical Relationships among Magnitude, Rupture Length, Rupture Width, Rupture Area, and Surface Displacement. Bull Seism Soc Am 84(4):974-1002

Wessel P, Smith WHF (1998) New improved version of Generic Mapping Tools released. AGU 79 47:579
Wyatt FK (1988) Measurements of Coseismic Deformation in Southern California: 1972-1982. J Geophys Res 93(B7):7923-7942

Yu SB, Chen HY, Kuo LC (1997) Velocity field of GPS stations in the Taiwan area. Tectonophysics 274:41-59

Yu SB, Kuo LC, Punongbayan R, Ramos EG (1999) GPS observation of crustal deformation in the Taiwan-Luzon region. Geophys Res Lett 26:923-926

Yu SB, Kuo LC (2001) Present-day crustal motion along the Longitudinal Valley Fault, eastern Taiwan. Tectonophysics 333:199-217

\section{Submit your manuscript to a SpringerOpen ${ }^{\circ}$ journal and benefit from:}

- Convenient online submission

- Rigorous peer review

- Immediate publication on acceptance

- Open access: articles freely available online

- High visibility within the field

- Retaining the copyright to your article

Submit your next manuscript at $\boldsymbol{\triangleright}$ springeropen.com 